\title{
Innovation Transfer Management in the Medical Sector
}

\author{
Malgorzata Nycz \\ Department of Artificial Intelligence Systems, \\ Wroclaw University of Economics, Wrocław, Poland
}

\author{
malgorzata.nycz@ue.wroc.pl
}

\begin{abstract}
This paper is devoted to the transfer of the innovative knowledge from those who possess it to those who could implement it into production (first of all the small and medium size enterprises $\mathrm{SME}$ ) and then deliver these innovative products into hospitals/clinics. It consists of 6 parts. After a brief introduction into the issue of the paper, we present concepts of information society and knowledge based economy, then we underline the role and importance of innovative knowledge diffusion within the medical sector. Part three has been devoted to the types of innovations. In part four we discuss the structure of innovation transfer management from medical staff to SME. The short conclusions end the paper.
\end{abstract}

Keywords: innovative knowledge, innovation transfer, knowledge management

\section{Introduction}

We are living in a very fast-changing world where the importance of information and knowledge is still growing. Our societies as well as economy are changing into information based society and our economy into the knowledge based one. These fast changes are important in any sector of economy. But the medical sector is especially important for inhabitants of modern countries because our health is one of the most important goods for us. Our health is also of importance to our state economy. If there is a need, we want to be treated in a hospital or a clinic with the best, as it is only possible, care using the newest innovative medical solutions in the patient treatment. When comparing the situation of hospitals 20-30 years ago and today, we see a huge progress. Bur there is still a lot to do in this field. Especially when we talk to e.g. doctors, nurses or laboratorial staff, we can often hear what should be done, in their opinion, to improve the level patient care, with better results for him/her, faster, with lower costs, etc. Nowadays, big business companies and corporations dominate as suppliers of finished innovative products. So far, changes initiated by the employees of clinics as well as small and medium-sized enterprises (SMEs) have no chance to transfer the knowledge and ideas into practice. But this is the flexibility of SMEs in

Material published as part of this publication, either on-line or in print, is copyrighted by the Informing Science Institute. Permission to make digital or paper copy of part or all of these works for personal or classroom use is granted without fee provided that the copies are not made or distributed for profit or commercial advantage AND that copies 1) bear this notice in full and 2) give the full citation on the first page. It is permissible to abstract these works so long as credit is given. To copy in all other cases or to republish or to post on a server or to redistribute to lists requires specific permission and payment of a fee. Contact Publisher@InformingScience.org to request redistribution permission. developing lab types, prototypes and small business solutions that can help to improve the day-to-day work of clinics and, especially, its quality. But they still have no or very limited possibility to share these ideas with those who could implement them into production and then deliver the new products to hospitals/clinics. Small and medium size enterprises are able to answer this challenge and quickly change their produc- 
tion line to fulfill these requirements and deliver new, innovative products to the market. But there is a problem: how and where these two sides can meet each other. In this paper we try to give possible solutions to this question.

\section{Information Society and Knowledge Based Economy}

For the last +-25 years we have observed new type of society coming into being - very innovative, based on information and knowledge. Fast progress in information technologies enables gaining, transmitting and analyzing of knowledge. Information society can be defined as a society in which information is a key element of the social and economic activities and changes. That is why the importance of an access to information in economy as well as in social life is still growing. There are many names to describe 'information society'. Among them the 'knowledge based society' is very popular.

One of the most important features of the information society is an intensive exploitation of knowledge. Knowledge and information should be managed. Their quality as well as how quick they are obtained by interested managers is crucial. These elements are competitive factors in industry, services and public administration. Managing an enterprise requires efficient knowledge as well as human capital management. We understand human capital as all assets that are acquired, maintained, developed, evaluated and supervised. Any organization, to be fully competitive on global and local markets, should fulfill two conditions (Kisielnicki, 2004): to possess knowledge and to be able to use the possessed knowledge.

In the information society the new type of economy, which is known as the knowledge based economy, arises. It is a new stage in economic entities development as well as whole societies. Knowledge as well as information becomes one of the most important assets, aside from raw materials, capital, and labor. Still increasing importance of: globalization, science, and knowledge, treated as bases of current changes, can be perceived as an important feature of the knowledgebased economy. The need for the knowledge as well as highly educated people is growing. Still increasing competition requires permanent growth of people's competence and a permanent learning.

The World Bank says that knowledge-based economy is based on the six following pillars: innovativeness, education, institutional and business surroundings, information and communication system, knowledge management in enterprises and regional conditioning.

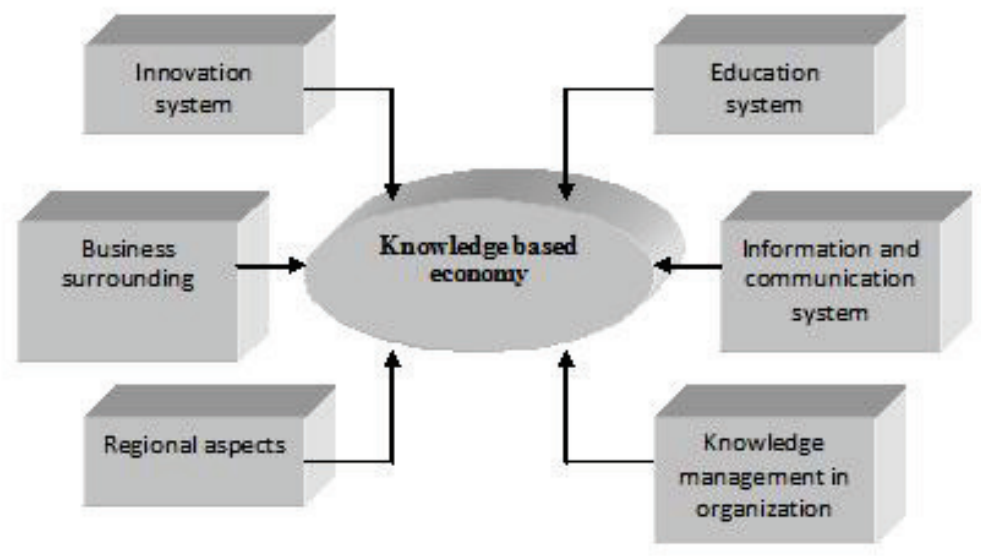

Figure 1. Six pillars of the knowledge based economy source: (Hejduk, 2004; Nycz, 2007) 
The knowledge-based economy is connected with the information society. We can treat the information society as a synonym of modernity, creativity, freedom, and prosperity of people. Its essence is information and knowledge as well as necessary tools (e.g. internet) that allow to access them. The information society is a part of the information economy (or new economy), which is a developed form of market economy. It can be characterized by dominant position of employment in information sector and intensive exploitation of information technology (Hejduk, 2004).

In the knowledge-based economy the role and importance of information and knowledge is still growing. Knowledge is becoming one of the most valuable assets in any organizations. Fast progress in the field of scientific research - especially in medicine, new information and communication technologies, etc. enforces not only the necessity for innovation transfers but also the necessity of developing and creating knowledge. Knowledge management can be seen as a result of evolutionary human development. In the last quarter of the $20^{\text {th }}$ century this development was observed in wider and wider application of information and knowledge in societies and organizations. Today information and knowledge are crucial and especially valuable due to the fact that progress in any sector of our life is still significant. Fast exchange of medical knowledge, new medicals, creation and propagation of new knowledge, etc. is possible due to the achievements of 'informational revolution'.

There are many descriptions and definitions of knowledge management (KM) in literature. For the purpose of this paper we propose the following definition:

Knowledge Management is such an approach that covers identification, collecting (storing), development, enlargement, co-usage of both material and non-material information assets in organization. Further our investigations will be based on this definition.

\section{The Role and Importance of Innovative Knowledge Diffusion in the Medical Sector}

Implementation of medical innovations is a process generated by topical networks called clusters. Innovation processes in the field of medicine, where scientific knowledge is created with an emphasis on scientific development and discovering a therapeutic path, are such processes due to which it is possible to broaden knowledge and make progress in medical sciences and clinical practice. Due to the level of education of its medical personnel, the clinics possess high innovation potential of a product, process, and service development. Until now, this innovation potential has been not sufficiently transferred to outputs, such as development of products by companies, intellectual property (IP) of production processes, and better healthcare. There are many reasons for such a situation. The impediments arise, among other things, from the fact that clinics are interested mainly in the effective management and patients' well-being, and industrial companies in economy and economic importance of where they dominate as providers. This is mainly a shortage of resources and chances to transfer knowledge and ideas into products that restricts small and medium-sized enterprises (SMEs) in making use of innovations initiated by clinics' personnel.

There are many projects on how to enable the contacts and open the path for the transfer of innovative ideas from medical staff to small and medium-size enterprises, e.g. the IntraMED-C2C project in which the author participates (2CE096P1 - CENTRAL EUROPE Programme 2007 2013). This project began to develop and provide the tools for small and medium-sized enterprises (on an European scale) to increase their access to the innovation potential in clinics. This will open up new markets for their products. Workshops may be a good tool for initiating SMEs' access to clinics. Within the project, in accordance with the needs of the regions, pilot workshops are arranged. 


\section{Types of Innovations}

According to the classical classification of innovations, the subject criterion is used. It divides innovations into: product innovations, manufacturing process innovations, and innovations in organization of production.

A product innovation is every change that bases on improving a product, which is already being produced, or extending a current product offer by a new one and launching it to market, while manufacturing process innovation (also known as the process innovation) is a change of manufacturing methods that are being used (Stawarz \& Niedbalska, 2012). The organizational innovation (procedural innovation) - in its narrow definition - is changes in organizing the manufacturing process, without organizational changes in their wider meaning. Product innovations can be an independent process, the same as process innovations and organizational innovations.

However, these types of innovations usually occur together, especially if production of a new product is impossible by using traditional manufacturing technology and solutions in the scope of organization of production; on the other hand - process innovations can force changes in the production structure and organization. In general, majority of process innovations more or less affect products, while product innovations often do not force any or serious changes in manufacturing technology or organization of production. One can meet the innovation taxonomy which includes such four types of innovations as:

- product innovation,

- process innovation,

- organizational innovation,

- marketing innovation.

First two types are described by a general name of Technological Product and Process Innovations (TPP), while the next two are called as Non-technological Innovations.

According to Polish Central Statistical Office (GUS) in Poland one can distinguish:

- Organizational and Technical Innovations - they include ventures connected with a change of production departments, workplaces, auxiliary departments (internal transport, storage management, etc.) are organized as well as undertakings connected with purchasing computer software, deploying computers into controlling and adjusting manufacturing processes, and installing computer networks.

- Modifications - minor technical or aesthetic changes of products, which are not a serious technical improvement (modernization), introduced to (e.g.) get a share in a new market segment.

Other classification of innovation is used according to the originality criterion connected with the first application of a new technical solution. According to this criterion, the first use of new knowledge in manufacturing process can be described as an innovation, and next applications are described as diffusion (dissemination). In practice, a literal copying of an innovation does not often occur because of the necessity to modify the solution itself as well as the way it can be implemented into production. Therefore, one can say about pioneering innovations (original, creative), which are results of solutions that have never been used in production so far, and adopted innovations (duplicating, imitative), which bring production and market benefits in a given place and time.

Another criterion of innovations classification is the scale of changes. According to this criterion, innovations are divided into radical (crucial, non-constant, revolutionary for production) and incremental (that facilitate production, small progress). Setting a borderline between these types is not an easy thing. A relative size of knowledge and capital investments on realization of an in- 
novation as well as a relative significance of its economic effects, consequences for the economy and enterprises that implement new solutions, could be criteria of the above division. Analyses of innovation processes prove that innovations that facilitate are dominating in the innovation stream, while radical innovations are very rare. They are connected with higher risk (e.g. because of technical solution oversights), require better developed external channels to get the indispensable information, and are able to trigger abrupt changes in economy. However, it does not mean that economic significance of incremental innovations can be omitted in analyses of innovation activity. They can be - as a result of a series of consecutive improvements - an important factor of improving the technical level of production and economic effectiveness.

In the discussion on types of innovations, the following categories will occur:

- Innovations in experiences - this type of innovation is not focused on a product or a process, but on a co-creation of customers' experiences. Traditionally, majority of products evolve together with technological changes, not changes that occur according to a customer, and a need to create a new approach to a product evolution, which will take into consideration a big amount of customers with different interests, levels of skills, needs, and desires, is more and more often emphasized. In order to do it, it is necessary to create a so-called experiences environment - a frame of reference that will allow an enterprise to acquire various experiences of co-creation with millions of customers.

- Social innovations - plenty of enterprises start to search for an inspiration in a social sector. Such innovations are implemented by enterprises that perceive needs of a society as possibilities to develop new ideas, demonstrate technologies, create new markets, and defeat problems that have not been solved for years on the joint of business and social sphere. Enterprises that try to solve problems in the scope of e.g. education, sport, healthcare, communication, stop treating this sphere as an area of a charity activity, but as a strategic area which require both public and private side to be involved.

- Lead user's innovations - enterprises, organizations, and individuals whose demand for specific products significantly exceeds trade standards. Lead users outstrip this tendency, so they can be recognized as an important source of innovations, especially those that have a crucial character.

\section{The Structure of Innovations Transfer Management}

Innovation management can be defined as a search, based on the resources owned, for such types of innovations that cause a situation when the innovation process becomes more effective in a confrontation with challenges that are issued to an organization by market, rivals and customers. It includes a choice of a new technique, technology, and organization of work, searching for new solutions and various ways to use them according to legal, economic and financial, administrative, social, structural and process, environmental, and strategic issues. Complexity of innovation processes demands a system approach to manage this sphere of activity. It is in accordance with what P.F. Drucker said: "innovation is an organized, systematic, and rational work". It is legitimate to create a conceptual structure of business activity management for every enterprise. It includes 5 categories: strategy, structure, technology, tasks, and people. 


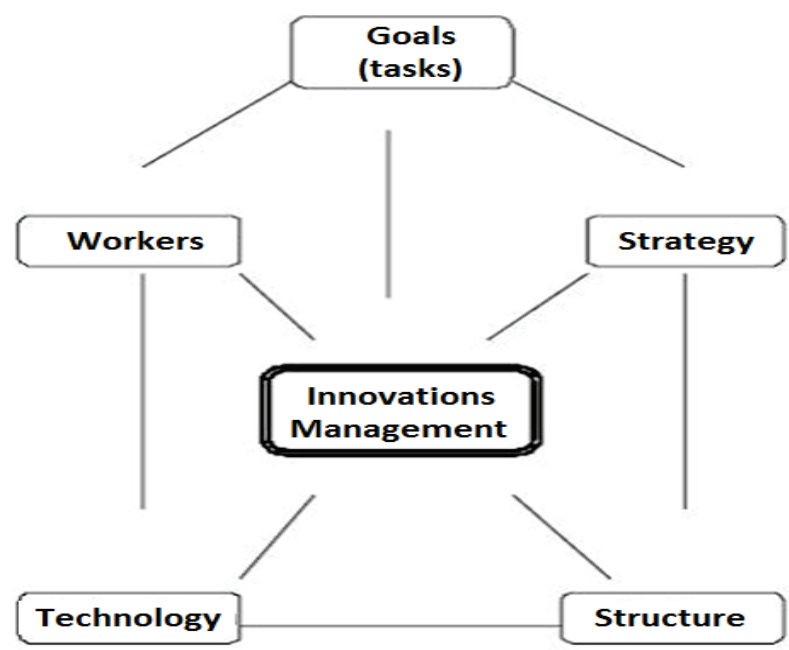

Figure 2. The model of conceptual structure of innovations management

Source: http://wpti.civis.org.pl/index.php?/W-\%C5\%BB/zarzadzanie-innowacjami-innovationmanagement.html, Retrieved November 13, 2012

A process approach to innovations management (that bases on integration of individual stages and actions that make up an innovation process, i.e., preparation of innovations and its effective implementation into practice and diffusion) is reasonable. Possibilities to perform such an approach to innovations management depend on resources and competences of enterprises. Big ones are able to organize the innovation process in a very extended way, coordinating many various stages and activities, while small enterprises usually work in an informal way.

Modern innovations management is characterized by the following features:

- a market orientation that take into consideration customer's expectations and rival enterprises;

- developed relations between science, innovations, and economy;

- creating a model of network which includes three mutually connected elements: entities (that take part in an innovation process), actions, resources;

- creating a system of information for enterprise needs on every stage of innovation process and for organizations that realize and implement innovations;

- creating factors, such as information and knowledge, that stimulate innovation development in organizations. A creation of new ideas and efficiency in transforming them into product, process, and service innovations is a sign of their development.

Knowledge transfer management can be perceived as a result of evolutionary development of a human. Information and knowledge are now important and especially valuable because of the fact that every area of our life is still developing. For some obvious facts: our health has a great significance not only for us (humans) but also for economies of our countries. So far, changes started by workers of clinics and small \& medium enterprises (SMEs) do not have a chance for knowledge and ideas transfer. However, their flexibility makes it possible to develop prototypes and small business forms that can contribute to the improvement of the healthcare sector everyday work and its quality. Because of the decision process, the company managers are the main factors that determine its success or failure. Therefore, they determine the level of interest in innovation products. Similar business processes exist on the side of healthcare units (Fig. 2.). Innovations management can be defined as searching, based on owned resources, for such types of innovations that cause a situation when the innovation process becomes more effective in a con- 
frontation with challenges that are issued by market rivals and patients. It includes a choice of a new technique, technology, and work organization, searching for new solutions and various ways to use them according to legal, economic and financial, administrative, social, structural and process, environmental, and strategic issues.

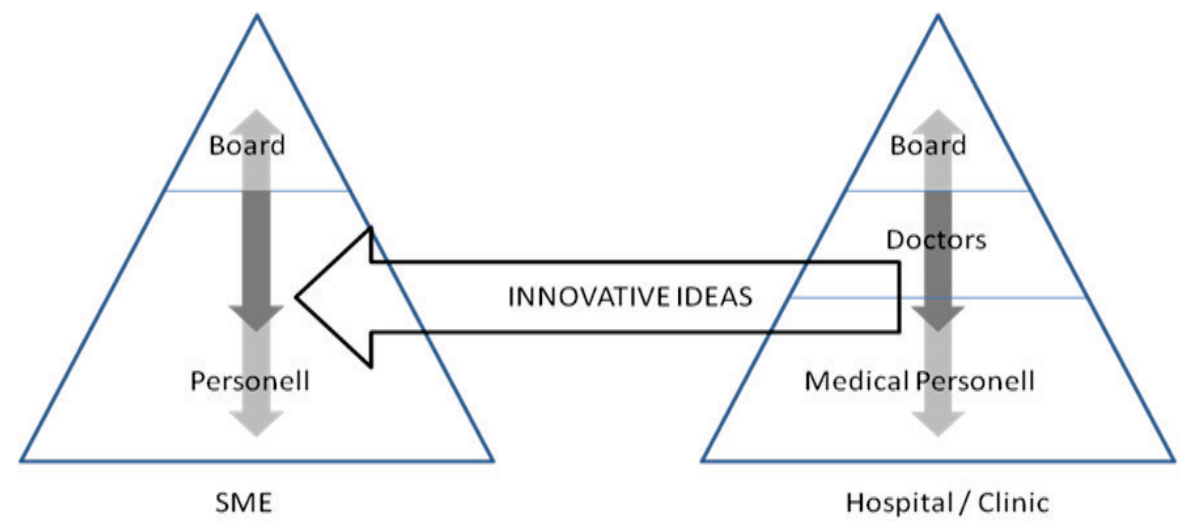

Figure 3. Structure of business processes in the innovation transfer Source: (Zwiefka, 2012)

According to the technological approach to knowledge management, the system of innovation transfer management can be seen as any other information system. It consists of three modules: input, processing and output. Among them, we distinguish feedbacks.

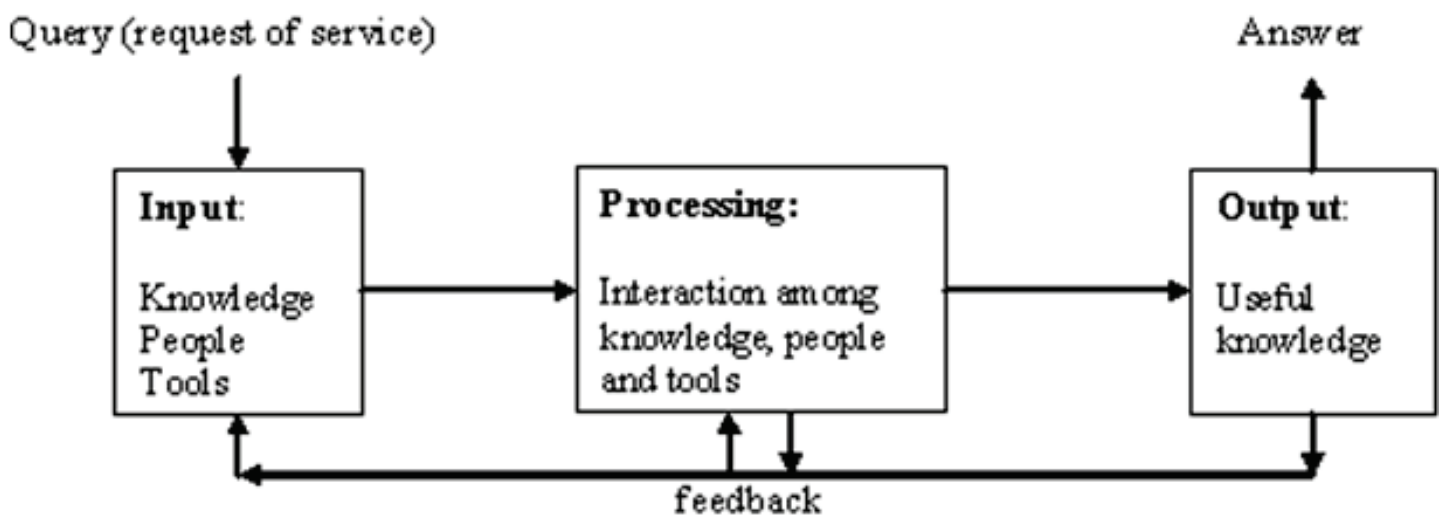

Figure 4. Model of innovation transfer management system

Source: based on (Nycz, 2007)

At the output of this model we obtain useful, innovative knowledge. We expect that this new knowledge delivers us such information as: where (who) is/possess innovative ideas, what kind of innovation it is, who (which firms) are interested in implementing this innovation and - potentially- who/which hospitals or clinics are interested in using this innovative solution. We expect that such a system should be perceived as a platform that enables 'meeting' those who have innovative ideas with potential producers, who could use these ideas into production of new, innovative products.

We see the possibility to put into practice the innovation transfer by using the internet platform. Under the term input we understand the place in the internet where those, who have innovative ideas, can be met by those producers, who are looking for new potentially innovative products they could produce and deliver to the market. The stage processing is this module of the communication platform where they can see each other and decide whether they want to cooperate and at 
what range, on what conditions, etc. The last module called output collects the results of the previous stage and can be a good invitation for the new visitors of the platform.

\section{Conclusions}

Our health is a subject of great importance not only to us (people) but also to our countries. On the other hand, medical clinics have a high intellectual potential for product innovation, process and service development. There are many reasons why this potential of innovation is not sufficiently transferred to the results, such as product development by companies and the health care system. In this paper we tried to say how the innovative solutions can be transferred from medical staff to potential producers, especially small and medium-sized enterprises, who are able to answer quickly to such requirements.

\section{References}

Hejduk, I. (Ed.) (2004). Przedsiębiorstwo przyszłości. Fikcja i Rzeczywistość, Instytut Organizacji i Zarządzania w Przemyśle „Orgmasz”

Kisielnicki, J. (2004). Kierunki i tendencje zastosowań informatyki we współczesnym zarządzaniu, Materiały seminaryjne z Konferencji. Polskie autorytety naukowe o komputerowych systemach wspomagania zarządzania. Centrum Promocji Informatyki

Nycz, M. (2007). Pozyskiwanie wiedzy menedżerskiej. Podejście technologiczne, Wyd. AE im. O.Langego we Wrocławiu

Stawarz, E., \& Niedbalska, G. (2012). Rodzaje innowacji. Retrieved November 13, 2012, from http://wpti.civis.org.pl/index.php?/O-R/rodzaje-innowacji-types-of-innovations.html

Zwiefka. A. (2012). [in] IntraMED-C2C project in which the author participate (2CE096P1 - CENTRAL EUROPE Programme 2007 - 2013

Zwiefka, A., \& Nycz, M. (2011). Management of knowledge acquisition from human sources in innovation transfer. In H-T. Hou (Ed.), New research on knowledge management technology, Chapter 3. InTech. Retrieved November 10, 2012, from http://www.intechopen.com/books/new-research-on-knowledgemanagement-technology

\section{Biography}

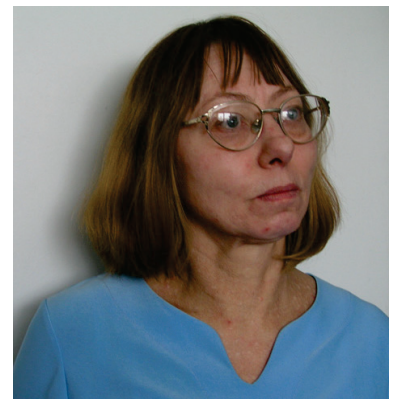

Prof. Malgorzata Nycz is a lecturer in the Faculty of Business Informatics, Wroclaw University of Economics, Poland. She has authored over 90 publications mostly oriented on intelligent systems topics, data warehousing and knowledge management. Her current research is connected with BI systems and business analytics as well as modern education including e-learning systems 